The Destructive Pattern: An Experiential and Existential Theory-building Case Study

Published as:

Gunst, E., \& Vanhooren, S. (2017). The destructive pattern: An experiential and existential theory-building case study. Person-centered \& Experiential Psychotherapies, Advance online publication. doi: 10.1080/14779757.2017.1396239

Ellen Gunst

FIDES, Psychiatric Center Sint-Amandus

Siebrecht Vanhooren

KU Leuven (University of Leuven)

Faculty of Psychology and Educational Sciences

Research Unit Clinical Psychology

siebrecht.vanhooren@kuleuven.be 


\title{
The Destructive Pattern: An Experiential and Existential Theory-building Case Study
}

\author{
Abstract \\ Darkness and destruction are as much part of human life as depression, anxiety, and joy are. \\ However, humanistic therapies - and especially the person-centered approach - have not been \\ very explicit about how to deal with clients who leave a trace of sexual and physical violence \\ behind them. The theory-building case study of Bruno not only helps us to broaden our \\ theoretical understanding about patterns of destructive functioning. It also shows how a \\ sustained effort in fostering the therapeutic relationship and the experiential processing of \\ painful traumatic experiences can lead to an improved affect regulation, self-soothing, and \\ self-acceptance. On an interpersonal and existential level, the client's growing capacity to \\ listen to his unfulfilled existential needs made him aware of his yearning for human \\ connection. It created also an openness to search for meaning in life and to connect with \\ others in a deeper and meaningful way.
}

Keywords: destructive pattern, existential, focusing, forensic, offenders 


\section{The Destructive Pattern: An Experiential and Existential Theory-building Case Study}

"What if someone like Darth Vader went to therapy?” Arthur Bohart (2013) asks himself this question in a chapter on person-centered therapy and the dark side of life. Bohart describes a fictional therapy session where doubts begin to surface in Darth Vader's mind. Darth Vader finds himself revisiting old experiences, he questions his constructs, and starts to open up to new experiences. Bohart shows how a person-centered approach can help clients to visit their darkest places; yet he remarks that his fictional case is oversimplified. In our experience, therapy with clients who commit crimes and who are dominated by their darker side is indeed more complicated.

The lack of real clinical case descriptions and the absence of a theoretical personcentered framework of how to work with these clients have challenged us to develop our own practice-based theory during the last decade (Baeke, Verbeeck, Debbaut, Decavel \& Gunst, 2009; Gunst, 2006, 2015; Vanhooren, 2006, 2011, 2015; Vanhooren, Leijssen \& Dezutter, 2015a, 2015b, 2015c, 2016, 2017). In our experience the client's destructive life experiences influence every aspect of the therapeutic process. As the client's relationship with the interpersonal world is often affected by his or her inner experience of threat, so is the therapeutic relationship. The therapist and the client are challenged to overcome - what we have called - a pattern of destructive functioning (Vanhooren, 2011). Based on our experiences with offenders in therapy, we discovered a recurrent pattern of experiencing the self and the world in our clients. They experience their inner world - and also the outside world - through a lens of threat (Vanhooren, 2011). Their perception seems to be narrowed; in their mind there is always danger around the corner. It is destructive because it harms their own inside world and their interpersonal relationships. They perceive their world as threatening, whether there is "real" danger or not. 
We observed two main types of destructive patterns (Gunst, 2015, Vanhooren, 2011). First there is the offensive destructive pattern. People who are stuck in this pattern of experiencing are easily triggered and seem ready to attack. They leave a trace of destruction and fear behind them. In their experience, they have to defend themselves constantly against potential danger. Their best way to control potential danger is gain control over the other. One way of staying in control is to frighten or to use violence against the other. Second, there is the defensive destructive pattern. People with this defensive destructive pattern react differently. Instead of controlling the other and being in the attacking mode, they seem to hide in their fortress with thick walls around their inner lives. The emphasis here lies on the control of their inner world. They suppress aggression and other emotions until it explodes in a very primitive (sometimes sexual) way. When it comes to an emotional outburst, they are unable to identify with what happened. Some people show a mix of these patterns by shutting down his whole inner self and terrifying the other. What these types have in common is a lack of introspection and an inability to reflect on (sometimes certain parts of) their inner world. As a consequence, they also experience a lot of relational problems, since they lack empathy and the ability to take a meta-stance to problems. At the heart of all of these patterns seems to lie a problem of affect regulation and a troubled history of attachments deficits at a young age (Vanhooren, 2011).

In this article we will put our initial theory of the patterns of destructive functioning to the test by what Stiles (2017) calls a theory-building case study. Theory-building case studies refine, enrich, or modify existing theories by comparing the initial theory with the observations in a particular case. Different than hypothesis-testing studies they don't focus on a singular statement which could be confirmed or rejected; theory-building case studies search to compare the theory as a whole with the reality of the case and aim to enrich the existing theory. As Stiles (2017) states, a key element is the linking of the observations in the case to 
the theoretical concepts. In our case study, we provided a theoretical interpretation after each stage of the case. We drew from our initial theory but expanded to other theoretical concepts when necessary. In our discussion and conclusion, we reflect upon the challenged theory and show how the case study enriched and extended the initial theory. At the same time, this theory-building case study of Bruno illuminates how a person-centered approach can help the client to establish an interpersonal and intrapersonal relationship in order to overcome a pattern of destructive functioning.

\section{Method}

Bruno, a 45 year old man, was the client of the first author. Because of the many challenges during the therapy, the first author was supervised by the second author in order to reflect and to find possible new directions. The client was informed about these meetings. In the supervision sessions during the therapeutic process we searched for a better understanding of the case by linking it to the theory of patterns of destructive functioning. Supervision was also helpful to support the therapeutic relationship and find ways in how to deal with the destructive pattern in therapy. The idea to publish this case was inspired by the fact that both authors were challenged to explore their initial ideas about destructive functioning and offender therapy.

Case studies give us the opportunity to examine unique life experiences in their own context and test existing theories (Merriam, 2009). The rough data of this case study consist of the therapy experiences seen through the lens of the therapist, the supervisor, and the client. The feedback of the client on this study has also been included. Throughout this article, important key sentences of the client are indicated by quotation marks. In order to guarantee the clients' anonymity, we gave the client the pseudonym 'Bruno'. For ethical reasons, we 
changed details in the description of the client. The client read the original and reviewed manuscript. He formally agreed to have the article published.

The therapy took place in an out-patient treatment center for sex offenders called FIDES (Forensic Institute for Sexual Deviance) in Belgium. This center developed a Multi Track Model of Relapse Prevention (Baeke et al., 2009). This treatment includes a cognitivebehavioral track, a contextual track, and a person-centered track. During the first year of treatment, our client Bruno followed the cognitive and the person-centered track, with weekly alternating sessions. Starting from the second year on, he continued this person-centered track; the cognitive behavioral track finished after a year. In total, Bruno's therapy took four and a half years, or 25 cognitive and 123 person-centered sessions. The female personcentered therapist had more than fifteen years of experience in person-centered psychotherapy with offenders. In Belgium, person-centered therapy has usually integrates the different tribes of the person-centered nation such as focusing-oriented psychotherapy, emotion-focused therapy, existential therapy, and the interactional approach (Lietaer, Vanaerschot, Snijders \& Takens, 2008). Depending on the client's needs, the therapist shifts during the therapy to a different person-centered approach.

The first part of our case-study will deal with the initial sessions (1-15) and will include the intake and background information. We will pay attention to Bruno's pattern of destructive functioning, his existential alienation, the importance of a holding environment, and affect regulation. The second part of the case-study will focus on the middle stages of the therapy (sessions 16-118). In this main body of the therapy, old injuries and traumatic experiences were processed. Step by step Bruno developed through focusing a different inner relationship which helped him to leave his destructive pattern behind. Focusing also initiated a search for meaning and helped him to discover his right to exist. Finally, there were the concluding sessions (sessions 119-123). Although at the end of therapy his life seemed to be 
more complicated and not all his problems were solved, Bruno asserted that he was certainly in a better place than ever before; not only for himself but also for his loved one's.

\section{Intake and the Early Sessions of Therapy (session 1-15)}

\section{Intake and Background Information (session 1 - 2)}

Bruno, a 45 year old man was referred to an out-patient program for sex offenders by a child protection service. This child protection service was warned by his wife who found child pornography on his computer. Since childhood the client had an unhealthy interest in sexuality. Bruno had a history of severe sexual abuse by his mother and extreme harassment by his peers. Although he had a hard time coping with his traumatic history, he did not want therapy for his traumatic experiences. He kept his emotions extremely under control and had episodes of binge eating. He did not mention a problem of aggression at first.

In the therapist's experience, Bruno's appearance was one of control. When he shook hands with her he almost crushed her fingers. She experienced tension and threat when she first met Bruno. During the intake, Bruno clearly kept control over his inner world and also over the intake. There was no room for exploration.

Bruno's initial appearance reminded us more of other violent offender clients than of typical sex offenders. Violent offenders often show a pattern of provoking fear and threat, which is commonly experienced by therapists as being endangered by or feeling unsafe with the client (Vanhooren, 2011). This could be a hint of the offensive type of destructive functioning. But Bruno was keeping his internal world under control as well. In terms of our initial theory, we experienced Bruno as a person who showed a mixed type of destructive functioning. Based on our previous experiences with these clients (Vanhooren, 2011), we 
could expect the first stage of Bruno's therapy to be marked by a struggle to establish a safe therapeutic and internal relationship.

\section{The early Sessions: Building a Holding Environment (session 3 - 15)}

During the first sessions, Bruno's mixed destructive pattern was very explicit. First, it became noticeable how he used different strategies to prevent contact with his inner world. As the therapist tried to ask questions about his childhood Bruno reacted hostile, defensive, and gruff. He warned the therapist he had a "second heart of black leather with different pipes that spread green poison which embittered others and his own life." In his mind, it was better to keep distance from his past and his feelings; intellectual reasoning helped him to block out emotional stress and conflict. Cleary, these strategies were not always successful. In this early stage even a single word could evoke an avalanche of emotions. The word "mother" filled him with rage which he acted out by beating on the wall during the session. In those moments he only experienced overwhelming sensations; there was no room for language or reflection. He was unable to express what was happening inside and he had no idea what filled him with anger at that moment.

Second, Bruno put the therapist in the expert position, although he dominantly prescribed what the therapist should do: she should break down his inner wall. He wanted to get rid of his emotions. He ordered the therapist to "conquer evil with evil and to have no mercy with him." For Bruno, a therapist was something like a surgeon who would perform her profession without personal involvement. Likewise he uttered that he was not concerned about other people; people had no meaning to him.

Bruno's presence reminded us of the existential alienation described by Ronel and Segev (2014). Bruno treated others - the therapist included - in an object-like way. He also objectified his own inner world and he commanded the therapist to "sweep it out." According 
to Ronel and Segev, one of the consequences of this objectification of the other is a growing lack of empathy. This leaves these clients in a vacuum of existential isolation and alienation. As a result their basic existential needs such as love and meaning are often unmet (Vanhooren et al., 2015a, 2015b). The client is basically interpersonally disconnected. As the other is experienced as object-like, the way is open to engage in destructive behavior in order to satisfy these unmet basic existential needs (Ronel \& Segev, 2014; Vanhooren et al., 2015a). From our point of view, clients with a mixed type of destructive functioning also objectify themselves, and as a result, are sometimes overwhelmed by emotions, chaos, or emptiness in the absence of a reflective inner relationship. Being overwhelmed by one's emotions - as Bruno often experienced - can be existentially alienating as well. Inspired by Martin Buber, Cooper (2015) describes this kind of inner relationship - in analogy to Buber's I-It relationship where the person treats the other in an object-like way - as a I-Me relationship: the client objectifies his or her inner world as a thing. The therapist will be challenged to bridge this outer and inner existential alienation.

This challenge became very tangible during this first stage of therapy; the therapist found it often hard not to run away from Bruno. Hoping that the client would gradually experience the therapeutic relationship as a safe place, the therapist tried to tolerate the troubled contact and to establish explicit boundaries. For example, she made clear that neither drinking alcohol before the session was not allowed nor physical aggression during the session.

The containment skills of the therapist were often put to a test. As the client could not verbalize what he experienced, the therapist needed to create a mental space for what could not be said yet (Vanhooren, 2011). In this space, the therapist develops empathy for the preverbal experiences of the client. What was new to us was that this holding environment is not only important for the client, but also for the therapist. The creation of a holding 
environment helped the therapist not to collude with the primitive defense mechanisms of the client. From this mental space, the therapist tried to attune to what was happening in the inner world of the client.

One way to strengthen this holding environment and empathy towards Bruno was a better understanding of the origins of his problems. For the therapist, theoretical understanding was helpful to keep her containing capacities open for this client. Knowing that Bruno had a history of severe sexual abuse by his mother and extreme harassment by his peers helped the therapist to cope with Bruno's behavior. Furthermore a deeper understanding of the etiology of destructive behavior was particularly helpful.

A follow-up study from a developmental perspective by Bierman (2007) describes how aggressive behavior is deeply rooted in a broader context of emotional development. Bierman argues that all children show aggressive behavior. Usually aggressive behavior turns into a more social and constructive way of handling problems. However, Bierman discovered that there are two groups of children who stay aggressive during the primary school. The first group of children has a rather good prognosis. They use aggression only as a means to be in power, but can also show social behavior and empathy. The use of physical aggression disappears with time. But the second group of children doesn't show a good prognosis at all. Aggression is not their only problem. They are not accepted by their peers because they lack a number of emotional and relational skills. There is a lack of empathy, they blame the others for their own behavior, ambiguous situations are usually experienced as threatening, they often interpret the other as hostile, they lack a safe sense of autonomy, they are hypersensitive to possible attacks on their autonomy, and they have a hard time understanding their own inner world. Bierman (2007) suggests that these children suffer from attachment problems.

There is evidence that childhood maltreatment and poor attachment interferes with the development of adaptive affect regulation capacities (Fonagy, Geregly, Jurist \& Target, 
2002). Abuse and threat during childhood can over-activate the amygdala during life. As a result, people are easily immersed in the subcortical route of information processing and perceive the outside world as a constant threat. This state of threat immobilizes the higher functions of the prefrontal cortex which are needed to engage in thoughtful reflection in order to integrate the experience (Siegel, 2001). Children who have been abused, neglected, or otherwise maltreated learn either to suppress and ignore their inner experiences (deactivating strategy) or to exaggerate emotions of fear, anger, sadness or hopelessness (hyper-activating strategy) (Cassidy, 1994; Crittenden, 2008). If milder strategies fail to gain comfort or safety in dangerous circumstances, children will develop more extreme strategies. Endangering strategies can be adaptive in dangerous contexts during childhood - eventually they can cause a lot of problems later in life (Baim \& Morrison, 2011). The deactivating strategy could lead to the defensive destructive pattern while the hyper-activating strategy could lead to the offensive destructive pattern. Violent and sexual behavior can be the result of emotion regulation problems (Howells, Day \& Wright, 2004) or can have an emotion regulation function (Gratz, Paulson, Jakupcak, \& Tull, 2009). Going back to the question of the etiology of a destructive pattern we can conclude these people not only suffer from disproportionately aggressive behavior, which is why we call it a destructive instead of an aggressive pattern. Behind the aggressive behavior, there is a broader emotional/relational problem, and in order for therapy to succeed, we need to address these underlying emotional issues as well.

\section{Processing Traumatic Experiences (session 16- 118)}

As is often the case with offenders (Maschi \& Gibson, 2012), Bruno's destructive pattern of experiencing the world could be linked to an unresolved traumatic experiences. Having been sexually abused by his mother, experiences of tenderness, vulnerability, and 
affection were coupled with feelings of being abused and harmed. In an act of self-defense and anxiety to be harmed, Bruno automatically reacted with defensiveness or aggression. His interest in child pornography could be understood as going back to his inner wound. It became clear that the only way to help Bruno was to process his early traumatic experiences.

As an additional theoretical framework for this part of the therapy, the therapist was inspired by Focusing-Oriented Therapy for Complex Trauma (FOTCT) (Phillips, 2014; Turcotte, 2011). In FOTCT recovery is understood as a staged process. The cycle of trauma and recovery is based on the medicine wheel from the Native American aboriginal culture. This wheel serves as a compass and describes the different stages of recovery. These stages are marked by the emotional process style of the client. This is in line with the Process Model of Affect Regulation (Kennedy-Moore \& Watson, 1999) which includes different dimensions of affect regulation (awareness, arousal, expression, acceptation and reflection). The East part of the wheel is completely occupied by the trauma. When a client is absorbed in that part of the wheel there is a traumatic bonding, a loss of identity, and different maladaptive coping strategies. Emotional arousal is extremely over or under-regulated. In this stage it is important to focus on emotion regulation skills and build an observer self to contain and to distance from the trauma. Regression must be recognized and worked with. The client must be separated from the trauma and stay within the therapeutic window. In the South part of the wheel there is an increasing emotion regulation and a growing capacity to observe instead of to relive. The ability to symbolize the experience is growing. The Western part shows a restored identity. The client is able to detach from the traumatic experience. He can look at it as something that happened and not as something he is. The reflective capacity improves which increases understanding of the inner experience and (inter)personal functioning. In the North of the wheel attachments are restored and the client is able to feel compassion for the self. The client experiences a growing freedom and a new openness to search for meaning in 
life. However, the process of recovery is not linear. The client can fall back to an earlier stage or switch in one session from one part to another.

\section{The East: Anger as a Defense Mechanism against Anxiety and Pain (session 16 - 28)}

When the therapy started to concentrate on processing traumatic experiences, the therapist tried to help Bruno to make a distinction between his anger part, his inner child, and healthy part. His rage was not only directed to his abusers but also to his inner child. He wished he could beat this part to dead in order to be released from his suffering. Bruno often got absorbed by his rage towards himself and experienced his trauma over and over again. The therapist tried to contain his unbearable feelings and actively brought him back in the here-and-now. She needed to be directive in separating Bruno from his traumatic experience. For example, she told him that he was at a safe place now in this very room with her. She asked him to look around and to notice objects such as the telephone in the room, the color of the carpet, etcetera. For Bruno it also was helpful to make eye-contact with the therapist. Although the therapist was not completely at ease, it was important to stay present with him during these overwhelming episodes. The therapist helped him to regulate his emotions, in order for him to learn that he "was" not his emotions but "had" emotions. The therapist also examined with the client which bodily signs predicted the overwhelming emotions of hurt or threat. There were moments where she actively put boundaries to the overwhelming quality of his emotions, by teaching him emotion regulation skills (counting down from ten to one, switching the focus to the here-and-now, making contact with his chair), or even by stating firm that it was enough for now. Looking at his experience from a distance was not possible in this stage. Sessions in this stage of the treatment were concentrated on modulation of arousal. Learning to how to contain and to tolerate extreme intense emotions was a challenge for both client and therapist. 


\section{The South: First Symbolizations and Self-In-Presence (session 29 - 72)}

The toddler and the hellhound. One of the basic problems with Bruno was the absence of a reflective inner relationship. Bruno suffered from under- and over-regulation of his inner experiences. Over-regulation means that the client controls his inner world in such a way that he or she might lose connection to the inner senses. Bruno's daily life was marked by this kind of over-regulation. He used binge eating or drinking as coping strategies in times of distress, but he didn't contact his inside world. However, there were often moments in therapy where he switched to under-regulation. For example, when the therapist tried to reach his inner experience Bruno immediately got overwhelmed. In reaction to intense painful feelings came anger or again a complete split-off. There were nonverbal signs of his inner struggle but he could not express himself verbally. It seemed as if he drowned or collapsed, and then suddenly exploded and disconnected. Yet he could not reflect on this experience. As a result, Bruno could not explore the meaning of what happened. Fonagy and Target (1995) call this a space without meaning; the client does not have the mental capacity to tolerate this experience and can't symbolize the experience. The experienced threat and abrupt ruptures of emotions shut down the capacity to sooth the mind, regulate the body, and to reflect about what is happening (Siegel, 2012). Little steps were taken in giving attention to bodily signs, in making the client more aware of his arousal state and his emotions, and in symbolizing what he came aware of.

The therapist was challenged to help Bruno to create a self-in-presence, i.e. a state of self that is witnessing and compassionate towards one's own inner aspects and processes (Weiser Cornell, 2013). Depestele (2004) speaks of a reflection space in which it becomes possible for the client to turn attention towards his or her own experiencing. In order to help 
the client to experience his emotions on a more workable distance, the therapist explicitly invited the client to look at what happened after being overwhelmed, or when he felt overwhelmed, to express his emotions in language. Symbolization in language and images helps us to unfold the implicit meaning of what we experience (Gendlin, 1996). In the long run, meaning also creates a stronger internal framework or identity and inner safety (Angus \& Greenberg, 2011).

However, in this stage of the therapy even the metaphors which seemed to capture the full implicit meaning of his experience overwhelmed Bruno. One of the first metaphors which came to him was "falling into a black bottomless cave." This image symbolized his experience of what happened to him just before he felt overwhelmed by rage. But even this image was too frightening. Another metaphor was a "sculpture that expressed a woman cuddling a child." For the client, this image symbolized a deep and unbearable yearning that he hardly could tolerate. When the therapist invited him to take some time to look to the sculpture from a distance, he immediately got flash backs of his mother abusing him. Afterwards he wanted to kill this yearning because it was a too painful experience.

Two sessions later Bruno told the therapist about a nightmare. He dreamed about a naked toddler and a hellhound. Focusing on the images of the dream enabled him - for the first time in therapy - to reflect on his inner experiences. Bruno could identify the naked toddler as his inner fragile child that yearned for affection and being held. When his inner child felt threatened, the hellhound attacked. At this point it felt impossible to connect with his inner child without being bitten by the hound. Feeling vulnerable was far too threatening. With these two symbols of very different inner parts, Bruno created a first reflective space and the possibility to reflect upon his experiences rather to drown in his emotions. 
Sunken Red. The therapist continued to foster language in order to facilitate expression of his emotional words and his underlying needs. Bruno read the war novel Sunken Red of Jeroen Brouwers, which facilitated a thread of symbolizations of his inner experiences and painful memories. For example, he remembered now how he discovered his father attempting to commit suicide when he was a six year old boy. Bringing this image in therapy, he lost his language again and in a couple of seconds he got overwhelmed by grief and anger. He started kicking the table in de therapy office. The difference this time was that he found more words afterwards.

In FOTCT, language tenses are used to separate the client from the past. In using the past tense, the body shows a memory (Phillips, 2014). When the client stammered some words: "panic", "alone", "my father is lying there", the therapist repeated in the past tense "when you saw your father lying there, you felt alone and in panic." The client needs to learn how to dip in and out this experience, and to learn that past experiences indeed happened in the past and not now. The client switched from being his traumatic experience to being a witness of it. For example, when the therapist asked what the little boy needed at that moment, Bruno could verbalize that he felt abandoned by his father. Furthermore, he could express his unfulfilled need to be protected by his father against his abusive mother.

His ability to reflect and to use language also grew regarding the anger towards his mother. When he thought about his mother, he experienced the need for revenge. Words that came up were disgust, repugnance, hate, and anger. He imagined injuring his mother. His anger was now clearly directed to her. It was important to acknowledge that his experience of anger was legitimate. When he was able to listen to his anger he could hear how his anger told him that he was worth living and to be taking care of. However, his anger also still functioned as a secondary emotion (Pascual-Leone, Gilles, Singh \& Andreescu, 2013) not to feel his pain and need. 
Learning how to listen to his inner experience at a distance made him feel like looking to his experience covered by a membrane. Sometimes he started missing the intensity of his emotions. With this membrane, his inner life almost felt inaccessible and distant. However, he really wanted to get rid of the intensity of his feelings. Step by step, it became possible to look at his inner experience and to find words or images without getting too much overwhelmed. This enabled him to develop a more healthy relationship towards his own experiences. Bruno recognized - while reflecting on his problems with others - that the clue of it all was that was all about his relation to himself. He could see how denying his inner life made it impossible to listen to what he really needed.

This discovery - that his basic existential needs were unmet by the lack of an inner relationship - made his existential alienation and isolation very tangible. During a later session (session 69) he explored and expressed more about his experience of deficiency. He named his anger as a reaction to a deep grief. When he acknowledged his grief he fell into a cave of existential loneliness. In contact with the therapist he could not or did not want to accept closeness because the cave could not be filled. Inwardly he felt like a child that was suffering from starvation.

\section{The West: Self-in-Presence with different self-aspects (session 73 - 96)}

The level of threat lowered during the therapy when Bruno started to reflect and to build a relationship with the different parts of his self. He started to acknowledge his anger part in the light of how people mistreated him in the past. He understood how his angry part was a shield to defend himself against inhuman and extreme harassments. His growing capacity to reflect helped Bruno to give meaning to his emotions. At the same time, he started to see how this continuous state of alarm was not necessary anymore. He was anxious to work with his angry part because he knew that it took control over him now and then. When he 
tried to put this dark part aside, he felt weak, alone, and unprotected. During session 76 for example, Bruno brought two pictures to therapy, which represented his "inner child beyond starvation" and his "hell hound." He didn't dare to look at these pictures because he felt scared of both of them. His inner child frightened him because of the confrontation with his pain and longing for human affection. At moments like this he felt that his inner child was crying to be held - although it was used to starvation, hopelessness, and longed to be dead. He knew his hell hound would break out as an act of self-defense as soon as he would allow himself to experience this longing for intimate connectedness. He started to understand that his dark side was trying to protect him from people who would abuse him instead of fulfilling his need of affection. Slowly he realized that keeping people away by being aggressive, his basic existential need for closeness would never be satisfied. When the therapist asked him if his hell hound could trust that he -as the grown-up adult - would take care of the child, he was touched and recognized his inner relationship problem.

In searching for ways to feel closer to others, Bruno took dancing lessons. Surprisingly, dancing felt safe to him. At moments, he could feel how his existential isolation was replaced by feeling completely accepted by the other. However, with experiencing this new closeness, Bruno also had to learn how to cope with missing this connection once the dance stopped. It would take much more sessions before Bruno could internalize this feeling of being connected.

Although Bruno was clearly doing better now, there were still moments where he was overwhelmed by his emotions. Especially when he was in touch with his inner deprived child, he felt completely absorbed. At times where he was able to take some distance from this emotion, he could see how his inner child needed safety and security. Although being aware of this need, he was unable to take care of his inner child. On the contrary, something inside himself wanted to get rid of this inner child and its yearnings, which he called 
"vernichtungsdrang" (the urge to destroy everything). The German word came up as the best fit to describe his inner experience. As the process of recovery is not linear, the client can lapse to an earlier stage. In a certain session, when his longing for affection became too strong, his "vernichtungsdrang" made him almost finish the whole therapy. Bruno started to doubt his goal of therapy: "Knowing how to deal with his past and feeling better." He wondered if he had aimed too high and he was thinking of quitting right away. In his own words, he wanted to "rip the therapy and the therapist" out of his life. The therapist insisted not to finish the therapy without a proper final session. Bruno didn't like this at all; when he decided to stop it was already over and he did not want to spend more time on separating. Although he was quite angry he showed up on the next session, which he didn't want to pay for. For Bruno, it was the therapist who demanded this session and not him. Paradoxically, her demand not to let him go was a sign for him that he really existed for her. Recognizing her authentic involvement and his own longing to live his life in a more free and more related way, he decided to come for another few months and even more frequent than before (weekly instead of every two weeks).

\section{The North: Self-Compassion and Existential Well-being (Session 97-118)}

Bruno slowly developed the capacity to listen to his bodily felt senses and to focus. The strong therapeutic relation and a new formed inner relationship made it possible for Bruno to dive into the focusing space (Depestele, 2004) now and then. Depestele (2004) characterizes this space by an listening accepting attitude of both the client and the listener to whatever comes. In one of those early moments words like "remorse", "self-compassion", and an image of a piece of burned wood came up when he listened to his vague bodily sensations. His first reaction towards these words and images were quite negative: "Drop it, this is worthless." When the therapist asked him to listen with openness and curiosity to this image, 
he was surprised to hear something like: "Restore me." In another session Bruno focused on the felt sense of his anger. Also this time focusing led to an unexpected result. At the heart of this anger, Bruno discovered a something like his "right to exist" and his "urge to mean something and to matter to another person.” Focusing helped him to get in touch with his deep existential needs, which contradicted his previous coping style of isolating himself from others and from himself.

During the following sessions the therapist actively taught him how to engage with his inner child and how to take care for his pain and his longings. Concretely, for five weeks the therapist sent him after every session a lesson from the e-course Getting bigger than what's bugging you (Cornell, 2010). It worked surprisingly well, although he struggled with a lesson about the radical acceptance of his inner experiences. The effect of these lessons was that he succeeded to be in touch with his inner child, even when he felt rejected by his wife from time to time, which created emotional turmoil. Although this started to feel safe and even fulfilling, it still didn't feel as safe as hiding in his bunker. There were moments were Bruno even felt anxious and unsafe, especially in contact with the therapist, because the end of the therapy was near by then. From time to time, this made him shift to his old coping style of dominating and threatening the therapist again. Supported by supervision the therapist succeeded in staying in contact with Bruno and his different parts. In fact, the therapist modeled the possibility of a steady experiencing self that wasn't blown away by the power of his inner child and his anger part. Experiencing the steadiness of the therapist and her acceptance, Bruno started to develop this same capacity. Eventually, he noticed that he started to sooth and to protect his inner child. Bitter sweet memories came to his mind of embracing his little children. It was accompanied by anger for the fact that he had been abused and mistreated, but at the same time he could experience the deep need of his inner deprived child. Empathy for his woundedness was emerging. He noticed that he allowed self-compassion, something he 
longed for but never thought he would actually experience it. Although Bruno did not fully reach the North part of the wheel yet, described as recovery and freedom, his self-worth was growing and he could allow himself the right to exist.

\section{Final sessions (sessions 119-123)}

The final stage of the therapy was bitter sweet for Bruno. The therapist became a real trustworthy person for him. He was a bit anxious of falling in his deep cave again, but there was also hope that he could take care for himself and his needs. The therapist - who never gave a present to a client before - read him the book "The Hug" of David Grossman in the last session and gave it to him as a kind of transitional object. He was deeply touched and thankful, although his journey was not what he had expected. Not all his problems were solved. His life was paradoxically often more complicated than before, but as he explained, "it is a better life for myself and for the people around me."

\section{Discussion and Conclusion}

We started our article with referring to Arthur Bohart's (2013) fictional case study with Darth Vader, the face of evil in the Star Wars movies (episodes IV-VI). In Bohart's case of Darth Vader, the client knows how to reflect on his inner life and seems to trust the therapist right from the start. Our case of Bruno illuminates that it takes a lot of work sometimes before clients with a pattern of destructive functioning can explore and reflect. At the core, Bruno's therapy process has been marked by the continuous effort of the client and the therapist to create a personal relationship with his inner self and his external world. Before therapy Bruno was existentially alienated and disconnected from both realms. His mode of being-in-the-world was defined by trying to be in control over his overwhelming emotions 
and over the others. However, his control was never absolute and outbursts such as aggression, binge eating, and depersonalized sexuality were frequent at times. In therapy, Bruno eventually learned to relate instead of to control. Instead of controlling his emotions, he learned to reflect on them. He even gained a basic understanding of his life story and created meaning. He also learned to see the therapist as an authentic human and learned how to relate to others in a different way. By building personal relationships with his inner self and the world, he stepped out of his existential loneliness and recognized his basic existential needs. Language was essential in creating these relationships. It was only by learning how to talk and to reflect on his experiences that the necessary space was created to relate with his self and his unmet needs towards others.

On a theory-building level, we discovered elements that affirmed of our initial theory about patterns of destructive functioning (Vanhooren, 2011), but we also discovered several weaknesses. This theory - based on our former therapeutic experiences with clients - proved its value as a phenomenological model to understand Bruno's problematic functioning during the intake (session 1-2) and the early stage of therapy (sessions 3-15). It helped us to link the referral information (child pornography, traumatic childhood, attachment, binge eating, aggressive behavior) with his dominative interpersonal style and his over-regulation of his emotions. Knowing that Bruno probably suffered from a mixed type of destructive functioning helped us to understand and foresee problems on the level of the therapeutic relationship and on the inner relationship. Our initial theory also helped us to identify the main therapy targets: (a) developing a safe therapeutic relationship and (b) developing a safe inner relationship. As a result, both the aggression and the attraction to child pornography would diminish.

However, the specificity of this case also illuminated different gaps in our initial theory. It became clear that our theory of destructive functioning was more - in the terms of 
Stiles (2017) - an explanatory than a treatment theory. It explained how destructive patterns evolve and it generated some basic ideas about treatment targets, but it lacked - in the case of Bruno - how to contain his presence and his overwhelming emotions. Our initial theory also didn't guide us in dealing with his poor affect regulation or how to develop an inner relationship. One key element in this therapy was the realization that the therapist - in order to contain Bruno's interpersonal style and his poor affect regulation - needed a holding environment too. For her, deepening her theoretical knowledge about affect regulation and its antecedents in attachment history helped her to prevent an empathic closure towards Bruno. On the contrary, a deeper phenomenological understanding opened her empathy for what could not be verbalized yet.

A second key element was the use of focusing-oriented therapy for complex trauma (FOTCT) as a treatment theory. Where our initial explanatory theory lacked guidelines how to deal with Bruno's traumatic childhood experiences and how to build a safer inner relationship, FOTCT provided us clear ideas about how therapy could evolve. Bruno could be situated in the East part of the medicine wheel; the therapist worked hard to help Bruno modulate his arousal. In the second stage (South part), Bruno became more aware of his bodily felt senses and started to symbolize ("The toddler and the hellhound"). Later on modulation of expression was on the foreground ("Sunken red"). The next stage (West part) was characterized by his growing capacity to reflect on his emotions. He became also more aware of the meaning of his problems in the context of his life story and he discovered his unmet basic existential needs. Finally (North part), the last sessions were marked by acceptance of his inner child, his need for protection and care, and his discovery that he had the right to exist and to mean something in life. His hard-earned insights paved the way for a deep internal, interpersonal, and existential change. The observation of Bruno's experiential 
and existential change - and his earlier existential alienation - helped us to widen our initial theory to the existential realm.

Although existential theory is sparse when it comes to offenders (Vanhooren, 2015), there are some clear links between offending, existential alienation (Ronel \& Segev, 2014), and the absence of meaning and search for meaning (Maruna, 2001). The case of Bruno reveals how the objectification of his external and internal relationships made him feel existentially isolated and cut-off from the experience of his basic existential needs such as love and intimacy. It was only with the emergence of his self-in-presence and the possibility to focus on his anger that he became fully aware of his existential isolation and his unfulfilled needs. Later on, focusing led also to an important existential realization that he had the right to exist and to experience his clear urge to matter to other people. This observation calls for a deeper integration of existential and experiential theory and practice, as has been suggested by Madison (2010), Leijssen (2014), and Vanhooren et al. (2015b).

As the case study indicates, more research is necessary at least in two domains that are possibly interconnected: the field of existential themes and experiential work, and difficulties in affect regulation on different dimensions (awareness and symbolization, modulation of arousal and expression, acceptance and reflection) and their evolution during treatment. Systematic case studies with process and outcome measurements could help us to gain a deeper understanding of affect regulation difficulties, experiential, and existential changes in clients with patterns of destructive functioning. Considering the deep relational problems of these clients, attention for the therapeutic relationship and other "common factors" (Wampold, 2015) are of the most importance in future systematic case studies. We fully agree with Bohart (2013, p. 67) when he underlines the importance of treating these clients as "fundamentally worthy of being respected as a person no matter how harmful or evil their behavior has been" and treating them as "someone capable of potentially wise and adaptive 
behavior...". Without a sound (and hard-earned) therapeutic relationship, we don't think any deep changes are possible with these clients.

Based on this case study, we can conclude that our initial theory had a certain value as an explanatory theory, but that it lacked a deeper base when it came to emotion regulation and existential issues. The case of Bruno broadened and deepened our view on the etiology of destructive functioning, and also on a treatment pathway to change control for connection and meaning in life. Focusing proved to be essential for this change in Bruno's case. Overall, an integrative experiential-existential model which also incorporates theories on emotion regulation and attachment theories would make our initial theory more complete.

The therapy process of Bruno and his therapist showed some of the obstacles and hindrances that one might encounter in working with clients with a destructive pattern of experiencing. Nevertheless, it also demonstrated that it is worth trying. We hope that this case-study might inspire many therapists and counselors in their work with offenders and prisoners. 


\section{References}

Angus, L. E., \& Greenberg, L. S. (2011). Working with narrative in emotion-focused therapy. Washington, DC: American Psychological Association.

Baeke, J., Verbeeck, N., Debbaut, D., Decavel, B., \& Gunst, E. (Red.) (2009). Sporen naar verandering. Behandeling van seksueel delinquent gedrag. Antwerpen/Apeldoorn: Garant.

Baim, C., \& Morrison, T. (2011). Attachment-based practice with adults: Understanding strategies and promoting positive change. Brighton: Pavilion Publishers.

Bierman, K.L. (2007). Anger and aggression: A developmental perspective. In T.A. Cavell \& K.T. Malcolm (Eds.), Anger, aggression and interventions for interpersonal violence (pp. 215-238). Mahwah, NJ: Lawrence Erlbaum Associates.

Bohart, A. C. (2013). Darth Vader, Carl Rogers, and self-organizing wisdom. In A. C. Bohart, B. S. Held, E. Mendelowitz, \& K. J. Schneider (Eds.), Humanity's dark side: Evil, destructive experience, and psychotherapy (pp. 57-76). Washington, DC: American Psychological Association.

Brouwers, J. (1988). Sunken Red. New York: New Amsterdam.

Cooper, M. (2015). Existential psychotherapy and counselling: Contributions to a pluralistic practice. Londen, UK: Sage publications.

Cornell, A. Weiser (2010). Get bigger than what's bugging you. Focussing resources. http://focusingresources.com/_private_e_course/GBE_Days1-5.pdf

Cornell, A. Weiser (2013). Focusing in clinical practice: The essence of change. New York, NY: Norton \& Company.

Cassidy, J. (1994). Emotion regulation: Influences of attachment relationships. Monographs of the society for research in child development, 59(2- 3), 228-249.

Crittenden, P. M. (2008). Raising Parents: Attachment. Parenting and Child Safety. Cullompton: Willan.

Depestele, F. (2004). Space differentiation in experiential psychotherapy. Person-centered 
and Experiential Psychotherapies, 3, 129-139.

Fonagy, P., Geregly, G., Jurist, E.L. \& Target, M. (2002). Affect Regulation, Mentalization, and the Development of the Self. NY: Other Press.

Fonagy, P. \& Target, M. (1995). Understanding The Violent Patient: The Use Of The Body And The Role Of The Father. International Journal of Psycho-Analysis, 76, 487-501.

Gendlin, E.T. (1996). Focusing-oriented Psychotherapy: A manual of the experiential method. New York, NY: Guilford Press.

Gratz, K. L., Paulson, A., Jakupcak, M., \& Tull, M. T. (2009). Exploring the relationship between childhood maltreatment and intimate partner abuse: Gender differences in the mediating role of emotion dysregulation. Violence and Victims, 24, 68-82.

Grossman, D. (2013). The Hug. The Overlook Press.

Gunst, E. (2006). Mannen in burchten: Echtheid als middel tot contact in dadertherapie. Tijdschrift Cliëntgerichte Psychotherapie, 44, 103-116.

Gunst, E. (2015). Empathie in een forensische setting, een huis met vele kamers. In G. Vanaerschot, N. Niccolai, \& M. Hebbrecht (Eds.), Empathie, het geheime wapen van psychiaters en psychotherapeuten. (pp. 110-124). Leusden : Diagnosis Uitgevers.

Howells, K., Day, A., \& Wright, S. (2004). Affect, emotions and sex offending. Psychology, Crime and Law, 10(2), 179-195.

Kennedy-Moore, E., \& Watson, J. C. (1999). Expressing emotion: Myths, realities, and therapeutic strategies. Guilford Press.

Leijssen, M. (2014). Existential wellbeing counseling. In G. Madison (Ed), Emerging Practice in Focusing- Oriented Psychotherapy. Innovative Theory, Applications and Practice (pp. 142-157). London: Jessica Kingsley Publishers. 
Lietaer, G., Vanaerschot, G., snijders, J. A., \& Takens, R. J. (2008). Handboek gesprekstherapie: De persoonsgerichte experiëntiële benadering. Utrecht: De Tijdstroom.

Madison, G. (2010). Focusing on existence: Five facets of an experiential-existential model. Person-centered \& Experiential Psychotherapies, 9, 189-204. doi: $10.1080 / 14779757.2010 .9689066$

Maruna, S. (2001). Making good: How ex-convicts reform and rebuild their lives. Washington, DC: American Psychological Association.

Maschi, T., \& Gibson, G. (2012). Schema behind bars: Trauma, age, ethnicity, and offenders' world assumptions. Traumatology, 18, 8-19. doi: 10.1177/1534765610395626

Merriam, S. B. (2009). Qualitative research: A guide to design and implementation. San Francisco, CA: Jossey-Bass.

Pascual-Leone, A., Gilles, P., Singh, T., \& Andreescu, C. A. (2013). Problem anger in psychotherapy: An emotion-focused perspective on hate, rage, and rejecting anger. Journal of contemporary psychotherapy, 43(2), 83-92.

Phillips, S. (2014, June 4-5). Finding a Way In: Working with Focusing-Oriented Therapy and Complex Trauma. Personal communication, Training in Belgium, Antwerp.

Ronel, N., \& Segev, D. (2014). How the "positive" can influence criminal behavior: Growing out of the criminal spin by positive criminology approaches. In D. Polizzi, M. Braswell, \& M. Draper (Eds.), Transforming corrections: Humanistic approaches to corrections and offender treatment. Second Edition (pp. 229-243). Durham, NC: Carolina Academic Press.

Siegel, D. J. (2001). Toward an interpersonal neurobiology of the developing mind: Attachment relationships, "mindsight," and neural integration. Infant mental health journal, 22(1-2), 67-94. 
Siegel, D. J. (2015). The developing mind: How relationships and the brain interact to shape who we are. Guilford Publications.

Stiles, W. B. (2017). Theory-building case studies. In D. Murphy, D. (Ed.) Counselling Psychology: A textbook for learning and practice. Wiley-Blackwell

Turcotte, S. (2011). Medicine wheel: cycle of complex trauma and recovery [Class handout]. Aboriginal Focusing-Oriented Therapy and Complex Trauma Program. Vancouver, BC: Justice Institute of British Columbia.

Vanhooren, S. (2006). Ergens tussen zwart en wit: Psychotherapie met daders van seksuele delicten vanuit cliëntgericht perspectief. Tijdschrift Cliëntgerichte Psychotherapie, 44, 85-102.

Vanhooren, S. (2011). Destructie en de therapeutische relatie: Veldverkenningen en overwegingen. Tijdschrift Cliëntgerichte Psychotherapie, 49, 6-24.

Vanhooren, S. (2015). Loss of meaning, meaning-making processes, and posttraumatic growth among prisoners. Unpublished doctoral thesis. Leuven, Belgium: KU Leuven.

Vanhooren, S., Leijssen, M., \& Dezutter, J. (2015a). Posttraumatic growth in sex offenders: A pilot study with a mixed-method design. International Journal of Offender Therapy and Comparative Criminology. Advance online publication. doi: $10.1177 / 0306624 X 15590834$

Vanhooren, S., Leijssen, M., \& Dezutter, J. (2015b). Posttraumatic growth during incarceration: A case study from an experiential-existential perspective. Journal of Humanistic Psychology, Advance online publication, 1-24. doi: $10.1177 / 0022167815621647$

Vanhooren, S., Leijssen, M., \& Dezutter, J. (2015c). Loss of meaning as a predictor of distress in prison. International Journal of Offender Therapy and Comparative Criminology. Advance online publication. doi: 10.1177/0306624X15621984 
Vanhooren, S., Leijssen, M., \& Dezutter, J. (2016). Profiles of meaning and search for meaning among prisoners. The Journal of Positive Psychology. Advance online publication. doi: 10.1080/17439760.2015.1137625

Vanhooren, S., Leijssen, M., \& Dezutter, J. (2017). Ten prisoners on a search for meaning: A qualitative study of loss and growth during incarceration. The Humanistic Psychologist, 45, 162-178. doi: 10.1037/hum0000055

Wampold, B. E. (2015). How important are the common factors in psychotherapy? An update. World Psychiatry, 14, 270-277. doi: 10.1002/wps.20238

BIO Authors

Ellen Gunst is a psychologist, and a person-centered experiential therapist, who works at the forensic unit FIDES for mid-security offenders in PC St.-Amandus, a psychiatric hospital in Beernem, Belgium. As a doctoral student at UGent (University of Ghent, Belgium) she investigates emotional change in sex offenders during treatment.

Siebrecht Vanhooren $(\mathrm{PhD})$ is an associate professor at KU Leuven (University of Leuven, Belgium) where he teaches person-centered, focusing-oriented, and existential therapy at 
graduate and postgraduate students. He also works as psychologist and therapist at PraxisP (KU Leuven) and at the forensic psychotherapy unit of CGG Prisma (Belgium).

\section{Acknowledgements}

We would like to thank Frans Depestele, Tine Swyngedouw, Chris Van de Veire, and Joke Van Hoeck (members of the Flemish study group Focusing in Therapy), the editor, and the reviewers of this manuscript for their theoretical consideration, therapeutic suggestions, and mental support during this therapy process. 